\title{
Review Article \\ Controlling Influenza by Cytotoxic T-Cells: Calling for Help from Destroyers
}

\author{
Michael Schotsaert, ${ }^{1,2}$ Lorena Itatí Ibañez, ${ }^{1,2}$ Walter Fiers, ${ }^{1,2}$ and Xavier Saelens ${ }^{1,2}$ \\ ${ }^{1}$ Department for Molecular Biomedical Research, VIB, 9052 Ghent, Belgium \\ ${ }^{2}$ Department of Biomedical Molecular Biology, Ghent University, 9052 Ghent, Belgium
}

Correspondence should be addressed to Xavier Saelens, xavier.saelens@dmbr.vib-ugent.be

Received 17 December 2009; Accepted 3 March 2010

Academic Editor: Zhengguo Xiao

Copyright (C) 2010 Michael Schotsaert et al. This is an open access article distributed under the Creative Commons Attribution License, which permits unrestricted use, distribution, and reproduction in any medium, provided the original work is properly cited.

\begin{abstract}
Influenza is a vaccine preventable disease that causes severe illness and excess mortality in humans. Licensed influenza vaccines induce humoral immunity and protect against strains that antigenically match the major antigenic components of the vaccine, but much less against antigenically diverse influenza strains. A vaccine that protects against different influenza viruses belonging to the same subtype or even against viruses belonging to more than one subtype would be a major advance in our battle against influenza. Heterosubtypic immunity could be obtained by cytotoxic T-cell (CTL) responses against conserved influenza virus epitopes. The molecular mechanisms involved in inducing protective CTL responses are discussed here. We also focus on CTL vaccine design and point to the importance of immune-related databases and immunoinformatics tools in the quest for new vaccine candidates. Some techniques for analysis of T-cell responses are also highlighted, as they allow estimation of cellular immune responses induced by vaccine preparations and can provide correlates of protection.
\end{abstract}

\section{Introduction}

Influenza is responsible for three to five million cases of severe illness and about 250000 to 500000 deaths each year worldwide (http://www.who.int/mediacentre/factsheets/fs211/en/index.html). These numbers, together with increased disease awareness and focus on pandemic preparedness, have contributed to the important growth of the market for influenza vaccines over the last years [1].

Current vaccines for seasonal and pandemic influenza come as inactivated whole virus, split virus, subunit vaccines, or live attenuated viruses [2]. They are produced starting from viruses grown on embryonated chicken eggs or in mammalian cell culture and some of them are combined with adjuvants. These conventional vaccines mainly aim to induce a strong humoral immune response directed against the hemagglutinin (HA) and the neuraminidase (NA) glycoproteins, the main antigenic determinants on the surface of influenza A and B virions. But the continuous accumulation of mutations in hot-spots of HA and NA that result in altered antigenic properties of these antigens dictates the need for annual updates of human influenza vaccines. As a result of this process, called antigenic drift, these vaccines induce effective protection only when the virus seed strains used for vaccine production antigenically match the circulating strains.

The process of antigenic drift could be driven by the selection of viruses with increased receptor binding avidity that emerge in vivo under the selective pressure of virus neutralizing antibodies [3].

Antigenic drift makes development and production of influenza vaccines challenging because the strains used for producing the vaccine for the coming season have to be selected by making predictions based on a worldwide survey of circulating strains by the World Health Organization Global Influenza Surveillance Network. Moreover, the seasonal vaccines should be available in the pharmacies shortly before or at the beginning of the next influenza season, but it is often difficult to predict when that will occur. Moreover, prediction of the next emerging pandemic strain 
is impossible. Collectively, these uncertainties impose risks for society and put extra pressure on vaccine producers. A vaccine that elicits protection against several clades within the same subtype or even induces heterosubtypic immunity (HSI), that is, protects against multiple influenza subtypes, would reduce this time pressure and allow more time for effective immunization. Such broadly reactive vaccines would also protect against newly emerging influenza subtypes that have epidemic or pandemic potential. The protective scope of seasonal protein vaccines can be broadened to some extent by administering them with adjuvants such as squalene-based MF59 (Novartis [4]) or AS03 (GlaxoSmithKline [5]), which have been licensed for human use. Some experimental adjuvants, such as ISCOMs (an immunostimulating complex already tested in humans $[6,7]$ ), and possibly also live attenuated vaccines, can induce substantial cellular immunity. The cellular arm of the immune system can provide HSI by inducing cytotoxic T cell (CTL) immunity directed against conserved influenza virus antigens $[8,9]$ and combining conserved immunogenic protein sequences from different influenza virus strains might result in a vaccine that protects against most current and future circulating influenza strains [10]. Another strategy for the induction of HSI shown to be effective in mouse models is based on raising immunity against the conserved proteins of the influenza virus. These include the matrix protein1 (M1) and matrix protein 2 (M2) or even only its ectodomain (M2e) [11-15], the internal nucleoprotein (NP) [16, 17], the nonstructural protein (NS1), and the polymerases (PA, PB1, PB2) [18].

Several of the new approaches aiming at the induction of HSI by targeting conserved influenza virus antigens are now in clinical trials, but none of them has made it to the market yet (http://clinicaltrials.gov/). For example, an M2e-based vaccine, developed in our laboratory [19], has successfully passed a phase I clinical study http://www.acambis.com/default.asp-id=2039.htm. The mechanism by which the M2e-based protein vaccine protects against a homologous or heterologous challenge in mice presumably relies on antibody-dependent cytotoxicity. In contrast, vaccines directed against the conserved internal influenza proteins are based mainly on the activation of cytotoxic $\mathrm{CD}^{+} \mathrm{T}$ cells. Less well understood are the contributions of $\mathrm{CD} 4^{+} \mathrm{T}$ cells to HSI during influenza infections. Besides their classical helper role, $\mathrm{CD}^{+} \mathrm{T}$ cells also exert a cytolytic effect on influenza-infected cells in mice [20]. In this review, we summarize the mechanisms that are essential to prime CTLs, how CTL-inducing vaccines should be designed, and how influenza virus-specific CTLs counteract influenza infection. In addition, we focus on the use of bioinformatics and easily accessible and searchable epitope databases to build better and novel CTL-based influenza vaccines. Finally, the analysis of vaccine efficacy and measurement of correlates of protection for CTL based vaccines against influenza is addressed. The technology to demonstrate and quantify pathogen-specific, functional CTL responses is now available in most immunology research laboratories but is still too complex for implementation in routine clinical biology laboratories.

\section{Mechanism of CTL Priming}

Before going into the challenges of developing successful CTL-dependent vaccines for influenza, we will briefly summarize the molecular mechanisms and cellular interactions required for induction of antigen-specific CTLs. The process of priming antigen-specific CTL is initiated when the Tcell receptor (TCR) of a naive $\mathrm{CD}^{+} \mathrm{T}$ cell binds a peptide presented by a major histocompatibility type I molecular complex (MHC-I) on an antigen presenting cell (APC). However, peptide recognition by the TCR alone is not sufficient to initiate a potent CTL response; activation of the $\mathrm{CD}^{+}$cell also requires a costimulatory signal provided by the binding of CD28 on the CTL to its ligand $\mathrm{B} 7$ on the APC [21]. Nevertheless, sometimes naive $\mathrm{CD} 8^{+} \mathrm{T}$ cells are not activated by interaction with APCs alone, and in such cases the bystander help of $\mathrm{CD} 4^{+} \mathrm{T}$ cells recognizing a related antigen on the same APC is required.

For an antigen to be presented properly on MHCI complexes, it typically has to be produced de novo in the cytosol. The endogenous protein is then degraded by the proteasome or other cellular proteases into peptides, which are transported to the endoplasmic reticulum (ER) by the transporter associated with antigen processing (TAP). Once in the ER, the peptides are loaded on the MHC-I molecules with the help of tapasin, and the stable MHC-Ipeptide complexes are transported to the cell surface of the APC. Of the licensed influenza vaccines mentioned above, only live-attenuated fulfill the requirements for de novo vaccine antigen production in the APC or the influenza virus-infected cell. The intracellular production of antigen during viral replication after administration of the coldadapted vaccine licensed in North-America [22] and Russia could, in principle, induce CTL-based immunity. Indeed, the induction of long-living and protective CTL-dependent HSI by live attenuated influenza viruses has been observed in mouse models [23]. However, it is unclear if such CTLbased HSI is also induced in humans and, if so, broadens the clinical protection afforded by live-attenuated compared to inactivated influenza vaccines. Noteworthy, however, is that exogenous antigens can also be presented on MHCI molecules by specialized APCs such as dendritic cells (DCs) by a process called cross-priming (reviewed in [24]). The priming of CTL responses by whole inactivated virus vaccines against influenza probably occurs after such crosspresentation [25].

MHC-I molecules in humans are also called human leukocyte antigens (HLAs). These HLAs show a high degree of polymorphism, making it possible that every individual has her/his personalized HLA. This HLA restriction imposes a severe constraint on the development of CTL-based vaccines because, from the same protein, different HLAmatching peptide epitopes are presented, and ideally all peptide antigens should be represented in the vaccine. What has been very helpful for vaccine design was the grouping of most HLA molecules into nine supertypes based on peptide binding specificities [26]. Therefore, if one wants to design a CTL-based vaccine that covers over $90 \%$ of the population, multiple or promiscuous epitopes that match most of the 
HLA supertypes have to be included. The situation is much simpler for experimental CTL vaccines that are evaluated in inbred mouse strains, as only one or few haplotypes are relevant for the population under investigation. In the quest for new epitopes (see also below), one should also consider the rank of an epitope in the immunodominance hierarchy respected by the host's immune system. A dominant epitope within a pool of foreign epitopes will by definition draw most of the immunological attention, resulting in a poor immune response to subdominant epitopes. This dominance, however, is not always fixed, because a second encounter with influenza (e.g., a later infection) may alter dominance hierarchies. The immunodominance hierarchy of $\mathrm{CD}^{+}$T-cells is dependent also on antigen dose and on T-cell precursor frequencies resulting from the previous infection [27]. The same principles of immunodominance might apply to vaccination. A subdominant epitope can gain an immunological lead over a dominant one because only the former was included in a vaccine or due to mutation of the dominant epitope. This will cause the relative immunodominance to change upon challenge [28, 29] because T-cell precursors specific for the subdominant epitope, raised by the prophylactic vaccine, are already present at the time of challenge. Therefore, it is important to have an idea about the immunohierarchy of different epitopes combined in one vaccine or present in different vaccines that are given together, and to make an adequate estimation of the preexisting pool of primed $\mathrm{T}$ cells already present in the host to be vaccinated.

\section{Protection by CTL Vaccines}

Once CTLs are primed by vaccination, they can recognize infected cells that present viral peptides on their MHC-I molecules. This implies that in a vaccinated individual at least one round of infection is needed for CTLs to exert their antiviral activity. Vaccine-primed CTLs can protect mice against a lethal influenza challenge [16], but because there is a gap in time between infection and viral clearance, morbidity cannot be prevented completely. The mild morbidity associated with CTL-based immune protection might be regarded as a drawback, but initial rounds of replication and the subsequent production of all viral antigens are essential for building stronger and more cross-protective adaptive immunity, as suggested by the data of Kreijtz et al. [30].

CTLs responses in small animal models are often analyzed in the spleen, one of the sites where antigen presentation takes place. The few rounds of infection that can occur in the presence of (cross)protective CTLs induced by CTL-based vaccines probably enable the presentation of antigen in secondary lymphoid organs and maybe even the formation of inducible bronchus-associated lymphoid tissue (iBALT) in response to influenza A virus infection. However, influenza-mediated induction of iBALT has been shown to be impaired after vaccination with an adjuvanted subunit vaccine against a human $\mathrm{A} / \mathrm{H} 3 \mathrm{~N} 2$ influenza virus, which induces an antibody response that is thought to neutralize the challenge virus [31]. It is important to appreciate the contribution to the adaptive immune response of iBALT formed in response to influenza A virus infection. This iBALT has been observed in both mice and humans after disease-related circumstances [32]. Distinct B-cell follicles and $\mathrm{T}$-cell areas as well as clearly defined germinal centers have been described in iBALT [33], and DCs are crucial for its organization and maintenance [34]. The adaptive response resulting from iBALT formation is protective in mice and can help contain the pulmonary infection even in the absence of peripheral lymphoid organs [33]. The iBALT contributes to the adaptive humoral immune response during influenza infection and it will be interesting to investigate whether the presence of protective influenza-specific T-cell precursors raised by vaccination can influence the composition, kinetics of formation, or role of iBALT. Deep pulmonary delivery of vaccines is of special interest here, as this technique allows the induction of antigen-specific cellular and antibody-mediated immunity, the latter at both the systemic and mucosal levels [35].

The few replication cycles allowed by the delayed protective mechanism of vaccine-induced CTLs may well allow the induction of CTLs and helper T- (Th) cells targeting antigens other than those included in the vaccine. Such responses can further promote heterosubtypic protection as discussed above. Bystander help from Th cells may consist of more than production of cytokines to promote antibody formation and isotype class switching. $\mathrm{CD} 4^{+} \mathrm{T}$-cells have also been reported to have perforin-dependent cytolytic effector functions that synergize with their bystander functions for $B$ cells after influenza infection [20]. On the other hand, CTLs are thought to kill infected cells after recognition of MHC-I-bound foreign peptides by delivering granzymes in a perforin-dependent way or by induction of apoptosis in the target cell by the Fas-pathway [36, 37]. The main task of CTLs is believed to be the rapid reduction of the viral titers in the lung by clearing infected cells [38]. Once the infection is contained by elimination of infected cells, antibodies that have been raised in the mean time can neutralize the remaining viruses. Moreover, new evidence suggests that $\mathrm{CD}^{+}{ }^{+} \mathrm{T}$ - cells might also provide bystander help. Like $\mathrm{CD}^{+}$helper T-cells, CD8 ${ }^{+}$T-cells are now classified into Tc1, Tc2, and Tc17 cells, according to the cytokines they produce [39-41]. As type 1 immune responses are needed to fight intracellular infections, CTL vaccines should ideally raise $\mathrm{Tc} 1$ instead of $\mathrm{Tc} 2 \mathrm{CD}^{+} \mathrm{T}$ cells. However, Oran and Robinson [42] showed that the induction of a Th2/Tc2 response against the influenza NP did allow the induction of a type 1 immune response at the site of infection. Paradoxically, $\mathrm{CD}^{+}{ }^{+}$T-cells are the main source of the antiinflammatory cytokine IL-10 in the lungs of mice infected with influenza A virus [43]. In this model, IL-10 mitigates the pathological effects that are associated with excessive CTL activity. However, this mitigation by IL-10 has to be carefully balanced because IL- 10 produced by $\mathrm{CD} 8^{+} \mathrm{T}$ cells also suppresses a protective Th17 response in the lung upon influenza infection. Naive IL-10 deficient mice control influenza A virus infection much better than wild type mice [44]. 


\section{CTL Vaccine Design}

Like all other vaccines, an ideal CTL vaccine should be easy to administer, effective, and safe. Vaccine efficacy means that the vaccine offers significant clinical protection against infection by the corresponding pathogen. A vaccine strategy that relies on CTL effector mechanisms should induce presentation of pathogen-derived epitopes to the immune system and result in the formation of a pool of CTLs with an effector phenotype that can retract into long-lasting memory. A prerequisite for efficient MHC-I-presentation of pathogen-derived peptides is that the antigen should either be produced intracellularly or be cross-presented after uptake. The former, far more efficient mechanism can be an achieved for example by use of an attenuated influenza strain, a heterologous viral vector expressing influenza virus antigens, or by gene vaccination.

Endosomal escape mechanisms have been shown to be effective in promoting cross-presentation of extracellularly administered antigens derived from tumors or pathogens. Cross-presentation of extracellular antigens can be enhanced by different means. One approach is to associate them with heat shock proteins $[45,46]$ or to use cross-presentation promoting systems based on lysteriolysin of L. monocytogenes $[47,48]$. Another approach involves encapsulation of the antigen in biodegradable particles that can be taken up by DCs $[49,50]$. Certain adjuvants can also help promoting cross-presentation [51].

Targeting conserved and immunodominant epitopes with CTL vaccines could offer protection during multiple influenza seasons and potentially against pandemic virus outbreaks. This is an attractive alternative for currently licensed influenza vaccines. But for the CTL approach to work, influenza antigen-specific CTLs should persist in sufficient numbers for a long time, at least until a booster signal is provided either by vaccination or by natural exposure to influenza virus. Help from $\mathrm{CD}^{+}{ }^{+} \mathrm{T}$-cells and a favorable cytokine environment are important during the retraction of CTLs into memory and for maintenance of these memory CTLs [52, 53]. By contrast, maintenance of $\mathrm{CD}^{+}$T-cell memory does not require persistence of antigen [54, 55]. Typically, memory $\mathrm{CD}^{+} \mathrm{T}$ cells are subdivided, according to the expression level of the homing receptors CCR7 and CD62L, in central memory T-cells (Tcm, CCR7 ${ }^{\text {high }}$ CD62 $\mathrm{L}^{\text {high }}$ ) and effector memory T-cells (Tem, CCR7 ${ }^{\text {low }}$ CD62 ${ }^{\text {low }}$ ). Tcm cells circulate in the blood and among secondary lymphoid organs, whereas Tem cells are found in peripheral tissue such as the lung as well as in the blood and spleen $[56,57]$. Tem cells are cytotoxic and act rapidly to defend against infection, but they do not proliferate. On the other hand, Tcm cells are responsible for clonal expansion of antigen-specific $\mathrm{CD}^{+} \mathrm{T}$-cells, which may result in the formation of new effector T-cells. However, an infection might not be contained before exhaustion of the residing pool of cytotoxic T-cells (consisting of preexisting Tem or CTLs recruited from the Tcm pool to the site of infection). In such cases, subsequent rounds of viral replication can take place. To avoid this situation, it is crucial to prime Tem in the lungs in order to contain an influenza virus challenge in the early stages of infection. This is a challenge that still hampers the development of effective CTL-based influenza vaccines.

When considering the safety of vaccines intended for humans, it is not only the direct side effects of vaccine administration that should be evaluated. Some vaccines are considered intrinsically safe because they do not replicate or result in de novo synthesis of the microbial antigen. These include peptide- or protein-based vaccines that rely on cross-priming for the activation of CTLs, such as virion like particles (VLPs), virosomes, ISCOMs [7, 58], inactivated viruses, or adjuvanted subunit vaccines. However, the situation is different when using attenuated pathogens or genetic vaccines. Live vaccines, for example, must have limited replication competence, be genetically stable, and not prone to gene swapping, and their use should be avoided in immuno-compromised individuals. The modified Vaccinia Virus Ankara (MVA) induces a potent humoral and cellular immune answer and has been shown to be very safe for use in humans, making it a good platform for the development of influenza vaccines (reviewed in [59]). MVA can replicate in human cells but it cannot produce mature MVA-particles because its structural proteins cannot be proteolytically processed in human cells [60].

Cold-adapted influenza viruses are another example of safe live vaccines. Their replication is restricted to the upper airways, and their infection is generally asymptomatic yet sufficient to induce a protective immune response. The issue of safety takes on a different dimension when considering vaccination with an expression plasmid [61], namely, the possibility that the plasmid DNA or part of it might integrate in the DNA of the host cells. The possibility of disrupting tumor suppressor genes or activating oncogenes as a result of such integrations remains a major concern. In addition, it is possible that long-term expression of the antigen at low levels might promote tolerance to the antigen. Finally, the risk of raising anti-DNA antibodies, which are present in patients with certain types of auto-immune disease, is another concern [62-66].

There are several infectious diseases for which CTLdependent pathogen control does more harm than benefit following a subsequent infection [67-69]. Exacerbation of disease by virus-specific CTLs has indeed been shown in the influenza mouse model [70, 71]. Given the potentially destructive nature of CTLs and by extension several other cell types of the immune system, it is not surprising that several feedback mechanisms control inflammation in general and contain excessive $\mathrm{CD}^{+}$T-cell activity specifically during infection [43, 72, 73]. Moffat et al. [74] investigated the expression levels of granzyme A (grzA) and B (grzB) in CTLs with different influenza $A$ virus antigen specificity during an influenza A virus infection. They concluded that CTLs specific for different influenza epitopes showed a hierarchy of grzA expression, and that this hierarchy inversely correlated with the magnitude of the CTL response. In the discussion they point to the study of Metkar et al. [75], who showed that both human and mouse grzA can stimulate monocytic cells to produce proinflammatory cytokines, a phenomenon that can worsen the outcome of an influenza infection 
[76]. Obviously, a safe CTL-based vaccine for influenza should be able to induce a protective CTL response without exacerbating the disease.

It is important to consider that most CTL epitopes of human influenza viruses that were identified until recently were highly conserved. However, to evade immune surveillance by CTLs, viruses have developed different mechanisms to prevent recognition by specific CTL. One of these mechanisms that appears to drive influenza A virus antigenic variation is the accumulation of mutations in or adjacent to CTL epitopes, which can affect peptide processing and presentation, binding to MHC class I molecules, and/or recognition by specific T-cells $[77,78]$.

\section{Novel Vaccine Design: What Can Databases and Prediction Algorithms Do for Us?}

Our understanding of T-cell biology and presentation of antigens by the immune system has grown considerably over the last decades. The exponential expansion of data available forces scientists to rely on bioinformatics tools to extract relevant information about epitopes of interest from several databases. To do this efficiently and accurately, these databases should be properly curated and transparent. Several general or pathogenspecific databases containing immune-epitope related data are available (reviewed in [79]). Databases often come with computational tools for optimal use of the resource. Worthy of mention is the recently redesigned Immune Epitope Database and Analysis Resource (IEDB), which is accessible at http://www.immuneepitope.org/ [80, 81]. This database is curated according to well-defined guidelines, allowing objective representation of immune epitope data gathered by the scientific community, and integrates these data with other knowledge resources [82-84]. In 2007, IEDB was used to inventorize the existing knowledge on influenza A epitopes [85]. That analysis provides a resource for influenza researchers and illustrates the possibility of identifying cross-reactive epitopes in different influenza strains, which might be of great value for the development of HSI-inducing vaccines. More recently, the IEDB was used experimentally to identify preexisting human $\mathrm{CD}^{+}$and $\mathrm{CD}^{+}$T-cell immunity against the pandemic A/H1N1/2009 influenza virus of swine origin [86]. The availability of immune-epitope related databases combined with a growing understanding of the events involved in antigen processing and presentation allowed the development of computational methods for prediction of novel T-cell epitopes for different species taking into consideration specific MHC alleles. The faster identification of immune-related data by use of the prediction tools allows the databases to be populated even more quickly. Many of these prediction tools are available through the internet (reviewed in $[79,87,88]$ ) and some of them are hosted by the IEDB. Guidelines and specifications are provided for the design and validation of computational models used for T-cell epitope prediction as well as assistance in selecting the most suitable prediction tools and selection criteria [89-91]. Especially for MHC-I-binding peptides, these tools have reached a level of accuracy that justifies their use in fundamental research and during the initial phases of vaccine development; they can substantially reduce the cost and workload associated with wet-lab validation of novel epitopes [92-94].

Similar to the study of Greenbaum et al. mentioned above [86], De Groot et al. [95] used immunoinformatics to compare T-cell epitopes contained within the pandemic A/H1N1/2009 influenza virus with those in the conventional vaccine used during the 2008-2009 flu season. Prediction of T-cell epitopes based on peptide-MHC-I binding is often successful [93], but a combination of binding affinities with predicted proteasome-mediated cleavage sites and estimated TAP affinity can further improve the accuracy of class I Tcell epitope prediction algorithms [96]. Combining multiple methods for predicting each individual step in the immune presentation process might even improve the predictive power [97]. On the other hand, including TAP affinity will eliminate TAP-independent peptides, which translates into a chance of excluding vaccine candidates from further investigation [91].

Vaccine design is also expected to benefit increasingly from immunomics, the study of immunological interactions between host and pathogen or host and antigen, including host-vaccine interactions. A combination of classical immunology and immunoinformatic tools is used for collecting, analyzing, and managing the huge amount of immune-related data currently available. Ultimately, a solid understanding of complex immune interactions might allow the modeling of complex host-pathogen or host-antigen interactions, thereby enabling us to study and predict more correctly the outcome of a vaccination $[98,99]$.

\section{Vaccine Efficacy and Correlates of Protection}

The measurement of vaccine antigen-specific humoral and cellular immune responses induced by vaccination can help to estimate the efficacy of a given vaccine. However, of even more importance for vaccine development is the degree to which these immune responses correlate with protection upon challenge. Since decades the serum antibody titer that inhibits hemagglutination (HAI) of red blood cells by influenza virions is the gold standard for determining the correlate of protection for the licensed influenza vaccines. According to the guidelines of the Food and Drug Administration, the effectiveness of an HA-based vaccine, including DNA vaccines expressing the HA gene, is measured as (1) the geometric mean HAI titer, and (2) the rate of seroconversion defined as the proportion of subjects with at least a fourfold rise of the HAI titer after vaccination (http://www.fda.gov/BiologicsBloodVaccines/Guidance ComplianceRegulatoryInformation/Guidances/Vaccines/ ucm074794.htm). These guidelines also take into consideration the pediatric population and the steadily growing group of adults over 65 years of age. The latter group has an increased risk of influenza-related disease and is 
considered a priority group for seasonal influenza vaccination. However, the antibody response to vaccination declines with age, which stresses the need for better influenza vaccines. However, it is not clear whether the induced HAI titer in a given test population provides equal confidence of protection against influenza disease in children, adults, and the elderly. McElhaney et al. compared serum HAI titers and ex vivo cellular immune responses to influenza vaccination in young adults and elderly adults ( $\geq 60$ years) $[100,101]$. They concluded that T-cell responses are better correlates of protection in the elderly. Nevertheless, as already mentioned in the introduction, antibodies against nucleoprotein are protective during influenza infection in a mouse model [102]. The mechanism by which these antibodies protect will almost certainly not be neutralization. Depending on the vaccine architecture and vaccination protocol, it is reasonable to expect that vaccination with CTL-vaccines targeting neutralization-insensitive internal proteins will also induce an antibody response, and it is therefore worth investigating whether the unintentionally induced antibody response also correlates with protection.

In contrast to the readouts for humoral responses upon vaccination, it is more difficult to apply practical and reproducible readouts that can be used as correlates of protection for cellular immunity. The importance of CTLs as correlates of protection in anti-influenza immunity has already been addressed elsewhere in depth $[103,104]$. We will limit the discussion here to some indications that CTLs correlate with protection during influenza infection in humans and focus on some techniques for functional analysis of T-cell responses.

There is limited evidence for CTL-mediated clinical protection during influenza infection in humans. The experimental infection study conducted by McMichael et al. [105] is the only study that directly shows a correlation between influenza-specific CTL activity and protection by measuring virus shedding. Epidemiological studies support these data but they rather document HSI without analysis of correlating specific CTLs in humans $[106,107]$. Ex vivo evidence for HSI due to CTLs in humans is provided by the observation of cross-reactive CTLs in PBMCs that recognize peptides derived from avian and swine influenza [108-110]. Finally, the variation in CTL epitopes observed in $\mathrm{H} 3 \mathrm{~N} 2$ viruses that have been circulating for 10 years suggests that these epitopes are under selective pressure, which is an indirect indication for the contribution of human CTLs to the antiviral activity directed against the major T-cell antigen of influenza A viruses [111].

\section{Techniques for Analysis of T-Cell Responses}

Estimation of T-cell activation ex vivo is relatively straightforward in a well-equipped immunology laboratory. Different assays are available, but they require more complex infrastructure than the HAI assay. For example, cytokine profiles are often analyzed in lung immune cells obtained from mouse bronchioalveolar lavage (BAL), peripheral blood mononuclear cells (PBMCs), or splenocytes after restimulation with antigen. Quantification of cytokines secreted in the medium by ELISA or by flow cytometry- (FC-) based techniques is often combined with techniques that allow exact counts of the number of cytokine-secreting cells, such as ELISPOT and intracellular staining of the cytokine (ICS) by flow cytometric analysis. The latter technique allows the functional characterization (phenotype, activation state, peptide restriction) of the cytokine producing cells by costaining of surface markers and tetramer stainings for epitope-specificity. The technical advancements made over the recent years have elevated the flow cytometer (FC) to an almost indispensable research tool for immunology and by extension for vaccine development. The most important advancements in this respect are its suitability for highthroughput screening and its quantitative output, which allows rigorous and statistically sound testing of hypotheses. Moreover, FC allows simultaneous multiparametric analysis of both humoral and cellular immune responses (reviewed in [112]).

CTLs contribute to protection by eliminating infected cells, which should reduce virus titers in the lung in the case of an influenza virus infection. Trying to find a correlation between killer capacities of CTLs and protection might therefore be relevant. Using human PBMCs with an in house-developed assay based on a substrate of grzB showed that grzB correlates with protection in the elderly, where protection was defined as absence of labarotory-diagnosed influenza virus $[101,113,114]$. The release of GrzB by killer cells into target cells can be detected by using fluorogenic probes based on the DNA-dependent protein kinase catalytic subunit, which is the substrate for grzB [115]. For many years, CTL activity has been estimated by a technique described more than forty years ago [116]. This technique measures the release of $51 \mathrm{Cr}$ from radioactively labeled target cells when they are killed by effector cells. Such release assays, however, do not have single cell resolution and as such do not allow any further characterization of the target and/or effector cells. Several techniques that can be used to estimate the killing activity by CTLs have been developed, some of which were borrowed from research in the cell death field. Staining of cleaved caspase 3 or using fluorogenic protease substrates can reveal induction of CTL-mediated apoptosis in the target cells $[115,117,118]$. Other FC assays, such as the FL-CTL and FATT-CTL, quantify CTL activity by monitoring the elimination of fluorescently labeled, transfected target cells after coincubation with effector cells $[119,120]$.

All the techniques mentioned above rely on ex vivo measurements of killing activity, sometimes after in vitro restimulation. Therefore the deprivation of killer cells from factors only available in vivo might bias the outcome and interpretation of a killing assay. A solution for this potential pitfall is the development of an in vivo killing assay in which CFSE-labeled target cells are adoptively transferred into mice and killing is followed using FC [121]. However, this limits the technique to investigations in experimental animal models. 


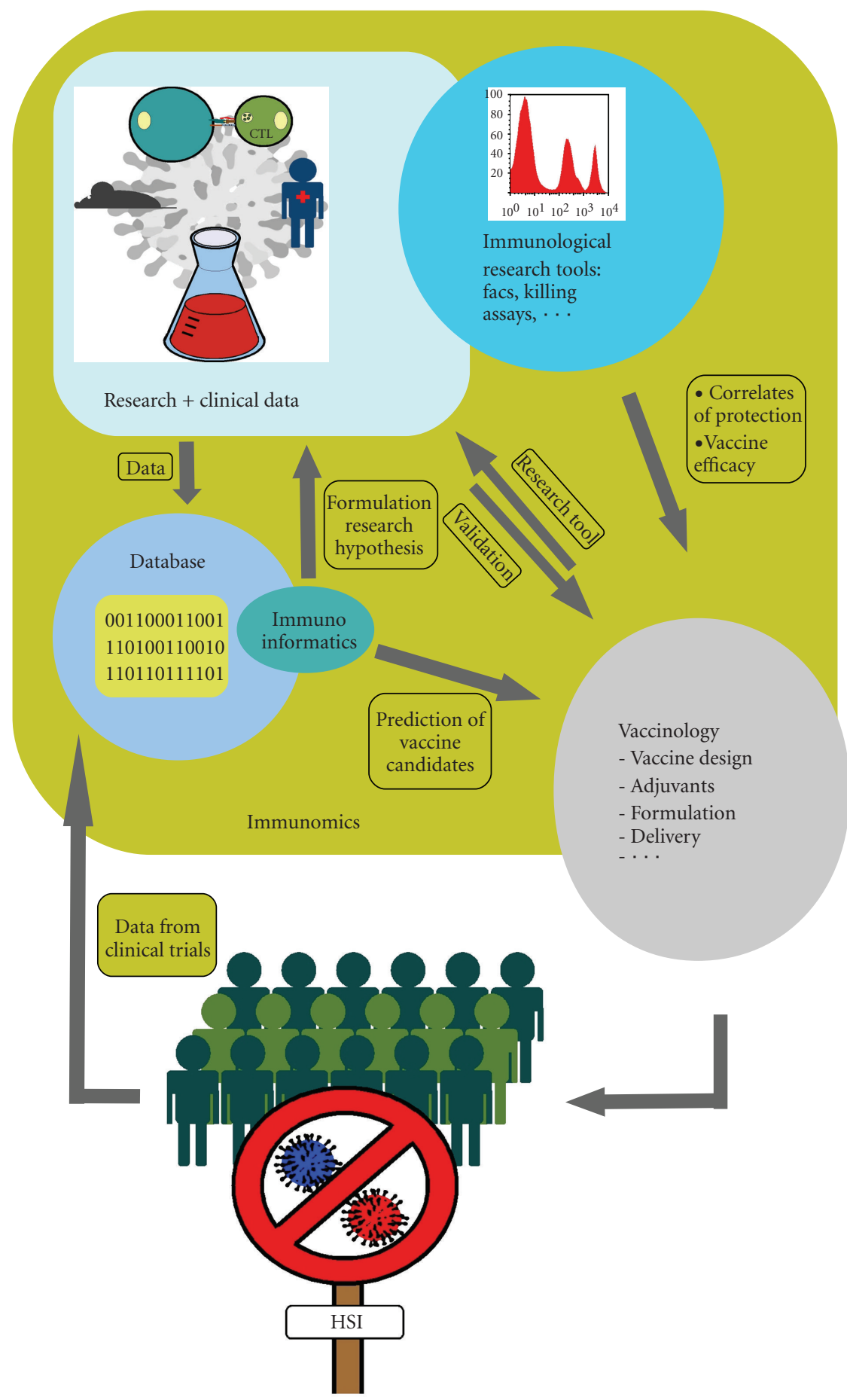

FIGURE 1: Immunomics comprises the study of immunological processes, thereby integrating new technologies and immunoinformatics tools from which the development of CTL vaccines can benefit. Immunoinformatics allows to collect, analyze, and manage data from research or the clinic into databases. This allows in return to formulate new research hypotheses or the prediction of new vaccine candidates. Promising epitopes are validated as vaccines in experimental set-ups or clinical trials. Hereby vaccines can be used as tools to address fundamental research questions, and immunological analysis can provide means to estimate vaccine efficacy or to determine correlates of protection. The many feed back loops in the system allow optimization of the development process and might ultimately result in a CTLbased vaccine that can induce heterosubtypic immunity against influenza. 


\section{Conclusions}

The need for influenza vaccines that induce HSI is not met by the current seasonal or pandemic (e.g., H1N1v-targeted) influenza vaccines, which rely on humoral immunity against HA and NA. Both the humoral and cellular branches of the immune system are involved in adaptive HSI (reviewed in [122]). The induction of HSI has been studied in animal models, but clearly defined general correlates of protection for HSI in humans are not available. The presence of virusspecific CTLs induced during a previous infection correlates with protection upon challenge with a heterologous virus in mice [30] and in humans [105]. The presence of HSI in a population might mitigate the clinical outcome of a newly emerging epidemic or pandemic influenza strain. Interestingly, it was recently shown in mice that effective vaccination with inactivated virus inducing $\mathrm{HAI}$ against an $\mathrm{A} / \mathrm{H} 3 \mathrm{~N} 2$ strain prevented the subsequent induction of HSI against an avian A/H5N1 influenza strain, which was efficiently mounted by prior infection of naïve animals with a human A/H3N2 strain [31]. The authors of this study state that these findings might have implications for vaccination strategies for children, who, early in life, are immunogenically naïve for influenza. Therefore, the question was raised whether we should first vaccinate this population with liveattenuated vaccines [123] or only start vaccination after a first natural infection, in which case a strong, cross-specific cellular immune response would be induced in response to the replicating virus. The vaccination of young children against influenza with current seasonal vaccines and the possibly reduced efficacy of induction of cellular immunity has been debated for several years [124-127]. HSI induced by CTL-based influenza vaccines is conceivable and might have major advantages over licensed influenza vaccines for this particular age group. CTL vaccines might make the aforementioned discussion obsolete because induction of CTLs, for example by DNA vaccination against the conserved internal genes, can take place in the presence of neutralizing antibodies directed against the surface molecules HA and NA induced by vaccination with classical vaccines. Also the elderly might benefit from CTL vaccines, as vaccine-induced $\mathrm{T}$-cell responses are better correlates of protection in this age group [100].

Immunoinformatic tools help us capturing, analyzing, and managing the massive amounts of immune-related data that has been gathered from experiments over the years and that continues to be generated every day. Large curated databases come with bioinformatics tools to optimize exploitation of the stored data and allow development of improved prediction tools for new vaccine candidates. Prediction tools can significantly speed up the process of discovering new epitopes by downscaling costly and laborintensive wet-lab experiments. The multidisciplinary field of immunomics will provide a platform for strategic vaccine research [128] and will aid in defining good correlates of protection for cellular immunity (see Figure 1). Recent research suggests that $\mathrm{T}$ - cell responses following infection or immunization are directed against a broader spectrum of epitopes than previously assumed [129]. The broader immune recognition does not conflict with the idea of immunodominance, as dominant epitopes still account for the major part of the CTL-response. The use of immunomic tools also helps to reveal subdominant epitopes. Including a selection of these epitopes in a CTL vaccine might improve the vaccine's protective capacity as well as induce HSI. As several cell types are involved in the activation of CTLs, the concept of CTL vaccines might be broadened to vaccines that also target other cell types. Induction of bystander help from $\mathrm{CD}^{+} \mathrm{T}$ cells might be as important for CTL activation as the binding of the epitope to MHC molecules for presentation purposes.

Some novel approaches for measuring T-cell activation are based on technologies that have not been widely integrated in immunology-related research. But these technologies might gain importance in future vaccine research and in the search for immune correlates of protection. For example, the nanoscale solid-state complementary metaloxide-semiconductor technology can measure T-cell activation in an antigen specific way within seconds, and it is therefore suitable for studying kinetics of T-cell activation [130]. Peptide-MHC microarrays, which were developed some years ago, allow fast and simultaneous activation, characterization, isolation, and identification of peptide-specific T-cell populations [131]. Newly emerging applications, such as those mentioned here, might find their way to large-scale epitope screens, and together with computational tools speed up vaccine discovery.

The challenge for vaccine research and development in the future is to integrate our current knowledge on immunology and T-cell biology in particular with immunoinformatic tools and immunotechnology into a higher-order system. Such a system will enable us to rapidly validate novel epitopes, which will provide us with the means to develop safe and efficient vaccines, such as the HSIinducing CTL vaccines discussed in this review.

\section{Acknowledgment}

The authors thank Dr. Amin Bredan for editing the manuscript and Dr. Karim El Bakkouri for critical reading of the manuscript and discussions. Michael Schotsaert was a beneficiary from a Bijzonder Onderzoeksfonds Research grant from Ghent University.

Lorena Itati Ibanez was a beneficiary from the Belgian Government (Federale Wetenschapsbeleid, BELSPO). Research related to M2e-based influenza vaccines in the group of X.S. is supported by FWO-Grant 3G037510, Ghent University IOF-Grant Step stone IOF08/STEP/001, and a research collaboration with Sanofi Pasteur.

\section{References}

[1] H. Kresse and H. Rovini, "Influenza vaccine market dynamics," Nature Reviews Drug Discovery, vol. 8, no. 11, pp. 841842, 2009.

[2] A. E. Fiore, C. B. Bridges, and N. J. Cox, "Seasonal influenza vaccines," Current Topics in Microbiology and Immunology, vol. 333, pp. 43-82, 2009. 
[3] S. E. Hensley, S. R. Das, A. L. Bailey, et al., "Hemagglutinin receptor binding avidity drives influenza a virus antigenic drift," Science, vol. 326, no. 5953, pp. 734-736, 2009.

[4] A. Banzhoff, M. Pellegrini, G. Del Giudice, E. Fragapane, N. Groth, and A. Podda, "MF59-adjuvanted vaccines for seasonal and pandemic influenza prophylaxis," Influenza and Other Respiratory Viruses, vol. 2, no. 6, pp. 243-249, 2008.

[5] I. Leroux-Roels, F. Roman, S. Forgus, et al., "Priming with AS03A-adjuvanted $\mathrm{H} 5 \mathrm{~N} 1$ influenza vaccine improves the kinetics, magnitude and durability of the immune response after a heterologous booster vaccination: an open non-randomised extension of a double-blind randomised primary study," Vaccine, vol. 28, no. 3, pp. 849-857, 2010.

[6] B. Morein, B. Sundquist, S. Hoglund, K. Dalsgaard, and A. Osterhaus, "Iscom, a novel structure for antigenic presentation of membrane proteins from enveloped viruses," Nature, vol. 308, no. 5958, pp. 457-460, 1984.

[7] G. F. Rimmelzwaan, N. Nieuwkoop, A. Brandenburg, et al., "A randomized, double blind study in young healthy adults comparing cell mediated and humoral immune responses induced by influenza ISCOM ${ }^{\mathrm{TM}}$ vaccines and conventional vaccines," Vaccine, vol. 19, no. 9-10, pp. 1180-1187, 2000.

[8] A. Mullbacher, G. L. Ada, and R. Hla, "Gamma-irradiated influenza A virus can prime for a cross-reactive and crossprotective immune response against influenza A viruses," Immunology and Cell Biology, vol. 66, no. 2, pp. 153-157, 1988.

[9] A. Mullbacher, M. Lobigs, M. Alsharifi, and M. Regner, "Cytotoxic T-cell immunity as a target for influenza vaccines," The Lancet Infectious Diseases, vol. 6, no. 5, pp. 255256, 2006.

[10] A. T. Heiny, O. Miotto, K. N. Srinivasan, et al., "Evolutionarily conserved protein sequences of influenza a viruses, avian and human, as vaccine targets," PLoS ONE, vol. 2, no. 11, article e1190, 2007.

[11] S. Neirynck, T. Deroo, X. Saelens, P. Vanlandschoot, W. M. Jou, and W. Fiers, "A universal influenza A vaccine based on the extracellular domain of the M2 protein," Nature Medicine, vol. 5, no. 10, pp. 1157-1163, 1999.

[12] M. Matsui, S. Kohyama, T. Suda, et al., "A CTL-based liposomal vaccine capable of inducing protection against heterosubtypic influenza viruses in HLA-A* 0201 transgenic mice," Biochemical and Biophysical Research Communications, vol. 391, no. 3, pp. 1494-1499, 2010.

[13] K. Mozdzanowska, J. Feng, M. Eid, et al., "Induction of influenza type A virus-specific resistance by immunization of mice with a synthetic multiple antigenic peptide vaccine that contains ectodomains of matrix protein 2," Vaccine, vol. 21, no. 19-20, pp. 2616-2626, 2003.

[14] A. M. Frace, A. I. Klimov, T. Rowe, R. A. Black, and J. M. Katz, "Modified M2 proteins produce heterotypic immunity against influenza A virus," Vaccine, vol. 17, no. 18, pp. 22372244, 1999.

[15] S. M. Tompkins, Z.-S. Zhao, C.-Y. Lo, et al., "Matrix protein 2 vaccination and protection against influenza viruses, including subtype H5N1," Emerging Infectious Diseases, vol. 13, no. 3, pp. 426-435, 2007.

[16] J. B. Ulmer, J. J. Donnelly, S. E. Parker, et al., "Heterologous protection against influenza by injection of DNA encoding a viral protein," Science, vol. 259, no. 5102, pp. 1745-1749, 1993.

[17] T.-M. Fu, L. Guan, A. Friedman, et al., "Dose dependence of CTL precursor frequency induced by a DNA vaccine and correlation with protective immunity against influenza virus challenge," Journal of Immunology, vol. 162, no. 7, pp. 41634170, 1999.

[18] J. R. Bennink, J. W. Yewdell, G. L. Smith, and B. Moss, "Antiinfluenza virus cytotoxic T lymphocytes recognize the three viral polymerases and a nonstructural protein: responsiveness to individual viral antigens is major histocompatibility complex controlled," Journal of Virology, vol. 61, no. 4, pp. 1098-1102, 1987.

[19] W. Fiers, M. De Filette, K. E. Bakkouri, et al., "M2e-based universal influenza A vaccine," Vaccine, vol. 27, no. 45, pp. 6280-6283, 2009.

[20] D. M. Brown, A. M. Dilzer, D. L. Meents, and S. L. Swain, "CD4 T cell-mediated protection from lethal influenza: perform and antibody-mediated mechanisms give a one-two punch," Journal of Immunology, vol. 177, no. 5, pp. 28882898, 2006.

[21] S. D. Norton, L. Zuckerman, K. B. Urdahl, R. Shefner, J. Miller, and M. K. Jenkins, "The CD28 ligand, B7, enhances IL-2 production by providing a costimulatory signal to T cells," Journal of Immunology, vol. 149, no. 5, pp. 1556-1561, 1992.

[22] R. B. Belshe, "Current status of live attenuated influenza virus vaccine in the US," Virus Research, vol. 103, no. 1-2, pp. 177185, 2004.

[23] T. J. Powell, T. Strutt, J. Reome, et al., "Priming with cold-adapted influenza A does not prevent infection but elicits long-lived protection against supralethal challenge with heterosubtypic virus," Journal of Immunology, vol. 178, no. 2, pp. 1030-1038, 2007.

[24] L. Shen and K. L. Rock, "Priming of T cells by exogenous antigen cross-presented on MHC class I molecules," Current Opinion in Immunology, vol. 18, no. 1, pp. 85-91, 2006.

[25] T. Sawai, Y. Itoh, H. Ozaki, et al., "Induction of cytotoxic T-lymphocyte and antibody responses against highly pathogenic avian influenza virus infection in mice by inoculation of apathogenic $\mathrm{H} 5 \mathrm{~N} 1$ influenza virus particles inactivated with formalin," Immunology, vol. 124, no. 2, pp. 155-165, 2008.

[26] A. Sette and J. Sidney, "Nine major HLA class I supertypes account for the vast preponderance of HLA-A and -B polymorphism," Immunogenetics, vol. 50, no. 3-4, pp. 201212, 1999.

[27] N. L. La Gruta, K. Kedzierska, K. Pang, et al., "A virus-specific $\mathrm{CD}^{+} \mathrm{T}$ cell immunodominance hierarchy determined by antigen dose and precursor frequencies," Proceedings of the National Academy of Sciences of the United States of America, vol. 103, no. 4, pp. 994-999, 2006.

[28] R. G. van der Most, K. Murali-Krishna, J. G. Lanier, et al., "Changing immunodominance patterns in antiviral CD8 Tcell responses after loss of epitope presentation or chronic antigenic stimulation," Virology, vol. 315, no. 1, pp. 93-102, 2003.

[29] J. Liu, B. A. Ewald, D. M. Lynch, A. Nanda, S. M. Sumida, and D. H. Barouch, "Modulation of DNA vaccineelicited $\mathrm{CD}^{+}$T-lymphocyte epitope immunodominance hierarchies," Journal of Virology, vol. 80, no. 24, pp. 1199111997, 2006.

[30] J. H. C. M. Kreijtz, R. Bodewes, G. van Amerongen, et al., "Primary influenza A virus infection induces cross-protective immunity against a lethal infection with a heterosubtypic virus strain in mice," Vaccine, vol. 25, no. 4, pp. 612-620, 2007. 
[31] R. Bodewes, J. H. C. M. Kreijtz, C. Baas, et al., "Vaccination against human influenza $\mathrm{A} / \mathrm{H} 3 \mathrm{~N} 2$ virus prevents the induction of heterosubtypic immunity against lethal infection with avian influenza A/H5N1 virus," PLoS ONE, vol. 4, no. 5, article e5538, 2009.

[32] T. Tschernig and R. Pabst, "Bronchus-associated lymphoid tissue (BALT) is not present in the normal adult lung but in different diseases," Pathobiology, vol. 68, no. 1, pp. 1-8, 2000.

[33] J. E. Moyron-Quiroz, J. Rangel-Moreno, K. Kusser, et al., "Role of inducible bronchus associated lymphoid tissue (iBALT) in respiratory immunity," Nature Medicine, vol. 10, no. 9, pp. 927-934, 2004.

[34] C. H. Geurtsvankessel, M. A. M. Willart, I. M. Bergen, et al., "Dendritic cells are crucial for maintenance of tertiary lymphoid structures in the lung of influenza virus-infected mice," Journal of Experimental Medicine, vol. 206, no. 11, pp. 2339-2349, 2009.

[35] A. Vujanic, J. L. K. Wee, K. J. Snibson, et al., "Combined mucosal and systemic immunity following pulmonary delivery of ISCOMATRIX ${ }^{\mathrm{TM}}$ adjuvanted recombinant antigens," Vaccine, vol. 28, no. 14, pp. 2593-2597, 2010.

[36] B. Lowin, M. Hahne, C. Mattmann, and J. Tschopp, "Cytolytic T-cell cytotoxicity is mediated through perforin and Fas lytic pathways," Nature, vol. 370, no. 6491, pp. 650 652, 1994.

[37] D. J. Topham, R. A. Tripp, and P. C. Doherty, "CD8 ${ }^{+}$T cells clear influenza virus by perform or Fas-dependent processes," Journal of Immunology, vol. 159, no. 11, pp. 5197-5200, 1997.

[38] R. M. Zinkernagel, "On natural and artificial vaccinations," Annual Review of Immunology, vol. 21, pp. 515-546, 2003.

[39] R. A. Seder, J.-L. Boulay, F. Finkelman, et al., " $\mathrm{CD} 8^{+} \mathrm{T}$ cells can be primed in vitro to produce IL-4," Journal of Immunology, vol. 148, no. 6, pp. 1652-1656, 1992.

[40] M. Croft, L. Carter, S. L. Swain, and R. W. Dutton, "Generation of polarized antigen-specific CD8 effector populations: reciprocal action of interleukin (IL)-4 and IL-12 in promoting type 2 versus type 1 cytokine profiles," Journal of Experimental Medicine, vol. 180, no. 5, pp. 1715-1728, 1994.

[41] H. Hamada, M. D. L. L. Garcia-Hernandez, J. B. Reome, et al., "Tc17, a unique subset of CD8 T cells that can protect against lethal influenza challenge," Journal of Immunology, vol. 182, no. 6, pp. 3469-3481, 2009.

[42] A. E. Oran and H. L. Robinson, "DNA vaccines: influenza virus challenge of a Th2/Tc2 immune response results in a Th2/Tc1 response in the lung," Journal of Virology, vol. 78, no. 8, pp. 4376-4380, 2004.

[43] J. Sun, R. Madan, C. L. Karp, and T. J. Braciale, "Effector T cells control lung inflammation during acute influenza virus infection by producing IL-10," Nature Medicine, vol. 15, no. 3, pp. 277-284, 2009.

[44] K. K. McKinstry, T. M. Strutt, A. Buck, et al., "IL-10 deficiency unleashes an influenza-specific Th17 response and enhances survival against high-dose challenge," Journal of Immunology, vol. 182, no. 12, pp. 7353-7363, 2009.

[45] F. Castellino, P. E. Boucher, K. Eichelberg, et al., "Receptormediated uptake of antigen/heat shock protein complexes results in major histocompatibility complex class I antigen presentation via two distinct processing pathways," Journal of Experimental Medicine, vol. 191, no. 11, pp. 1957-1964, 2000.

[46] A. A. R. Tobian, C. V. Harding, and D. H. Canaday, "Mycobacterium tuberculosis heat shock fusion protein enhances class I MHC cross-processing and -presentation by B lymphocytes," Journal of Immunology, vol. 174, no. 9, pp. 5209-5214, 2005.
[47] G. Ikonomidis, Y. Paterson, F. J. Kos, and D. A. Portnoy, "Delivery of a viral antigen to the class I processing and presentation pathway by Listeria monocytogenes," Journal of Experimental Medicine, vol. 180, no. 6, pp. 2209-2218, 1994.

[48] P. Q. Hu, R. J. Tuma-Warrino, M. A. Bryan, et al., "Escherichia coli expressing recombinant antigen and listeriolysin $\mathrm{O}$ stimulate class I-restricted CD8 ${ }^{+} \mathrm{T}$ cells following uptake by human APC," Journal of Immunology, vol. 172, no. 3, pp. 1595-1601, 2004.

[49] S. De Koker, B. G. De Geest, S. K. Singh, et al., "Polyelectrolyte microcapsules as antigen delivery vehicles to dendritic cells: uptake, processing, and cross-presentation of encapsulated antigens," Angewandte Chemie International Edition, vol. 48, no. 45, pp. 8485-8489, 2009.

[50] H. Shen, A. L. Ackerman, V. Cody, et al., "Enhanced and prolonged cross-presentation following endosomal escape of exogenous antigens encapsulated in biodegradable nanoparticles," Immunology, vol. 117, no. 1, pp. 78-88, 2006.

[51] A. Heit, F. Schmitz, M. O’Keeffe, et al., "Protective CD8 T cell immunity triggered by CpG-protein conjugates competes with the efficacy of live vaccines," Journal of Immunology, vol. 174, no. 7, pp. 4373-4380, 2005.

[52] D. J. Shedlock and H. Shen, "Requirement for CD4 T cell help in generating functional CD8 T cell memory," Science, vol. 300, no. 5617, pp. 337-339, 2003.

[53] J. T. Harty and V. P. Badovinac, "Shaping and reshaping CD8 ${ }^{+}$T-cell memory," Nature Reviews Immunology, vol. 8, no. 2, pp. 107-119, 2008.

[54] A. Mullbacher, "The long-term maintenance of cytotoxic T cell memory does not require persistence of antigen," Journal of Experimental Medicine, vol. 179, no. 1, pp. 317-321, 1994.

[55] K. Murali-Krishna, L. L. Lau, S. Sambhara, F. Lemonnier, J. Altman, and R. Ahmed, "Persistence of memory CD8 T cells in MHC class I-deficient mice," Science, vol. 286, no. 5443, pp. 1377-1381, 1999.

[56] F. Sallusto, J. Geginat, and A. Lanzavecchia, "Central memory and effector memory $\mathrm{T}$ cell subsets: function, generation, and maintenance," Annual Review of Immunology, vol. 22, pp. 745-763, 2004.

[57] F. Sallusto, D. Lenig, R. Forster, M. Lipp, and A. Lanzavecchia, "Two subsets of memory $\mathrm{T}$ lymphocytes with distinct homing potentials and effector functions," Nature, vol. 401, no. 6754, pp. 708-712, 1999.

[58] S. Sambhara, S. Woods, R. Arpino, et al., "Heterotypic protection against influenza by immunostimulating complexes is associated with the induction of cross-reactive cytotoxic T lymphocytes," Journal of Infectious Diseases, vol. 177, no. 5, pp. 1266-1274, 1998.

[59] G. F. Rimmelzwaan and G. Sutter, "Candidate influenza vaccines based on recombinant modified vaccinia virus Ankara," Expert Review of Vaccines, vol. 8, no. 4, pp. 447-454, 2009.

[60] G. Sutter and B. Moss, "Nonreplicating vaccinia vector efficiently expresses recombinant genes," Proceedings of the National Academy of Sciences of the United States of America, vol. 89, no. 22, pp. 10847-10851, 1992.

[61] J. A. Wolff, R. W. Malone, P. Williams, et al., "Direct gene transfer into mouse muscle in vivo," Science, vol. 247, no. 4949, part 1, pp. 1465-1468, 1990.

[62] J. J. Donnelly, J. B. Ulmer, J. W. Shiver, and M. A. Liu, "DNA vaccines," Annual Review of Immunology, vol. 15, pp. 617648, 1997. 
[63] H. W. Temin, "Overview of biological effects of addition of DNA molecules to cells," Journal of Medical Virology, vol. 31, no. 1, pp. 13-17, 1990.

[64] J. A. Wolff, J. J. Ludtke, G. Acsadi, P. Williams, and A. Jani, "Long-term persistence of plasmid DNA and foreign gene expression in mouse muscle," Human Molecular Genetics, vol. 1, no. 6, pp. 363-369, 1992.

[65] H. A. Smith, "Regulatory considerations for nucleic acid vaccines," Vaccine, vol. 12, no. 16, pp. 1515-1519, 1994.

[66] J. S. Robertson, "Safety considerations for nucleic acid vaccinese," Vaccine, vol. 12, no. 16, pp. 1526-1528, 1994.

[67] P. J. M. Openshaw and J. S. Tregoning, "Immune responses and disease enhancement during respiratory syncytial virus infection," Clinical Microbiology Reviews, vol. 18, no. 3, pp. 541-555, 2005.

[68] W. Huisman, B. E. E. Martina, G. F. Rimmelzwaan, R. A. Gruters, and A. D. M. E. Osterhaus, "Vaccine-induced enhancement of viral infections," Vaccine, vol. 27, no. 4, pp. 505-512, 2009.

[69] R. H. Mealey, S. R. Leib, M. H. Littke, B. Wagner, D. W. Horohov, and T. C. McGuire, "Viral load and clinical disease enhancement associated with a lentivirus cytotoxic T lymphocyte vaccine regimen," Vaccine, vol. 27, no. 18, pp. 2453-2468, 2009.

[70] J. Simeckova-Rosenberg, Z. Yun, P. R. Wyde, and M. Zouhair Atassi, "Protection of mice against lethal viral infection by synthetic peptides corresponding to B- and T-cell recognition sites of influenza A hemagglutinin," Vaccine, vol. 13, no. 10, pp. 927-932, 1995.

[71] D. Moskophidis and D. Kioussis, "Contribution of virusspecific $\mathrm{CD}^{+}$cytotoxic T cells to virus clearance or pathologic manifestations of influenza virus infection in a $\mathrm{T}$ cell receptor transgenic mouse model," Journal of Experimental Medicine, vol. 188, no. 2, pp. 223-232, 1998.

[72] J. S. Haring, V. P. Badovinac, and J. T. Harty, "Inflaming the $\mathrm{CD}^{+}$T cell response," Immunity, vol. 25, no. 1, pp. 19-29, 2006.

[73] K. M. Grebe, H. D. Hickman, K. R. Irvine, K. Takeda, J. R. Bennink, and J. W. Yewdell, "Sympathetic nervous system control of anti-influenza CD8 ${ }^{+}$T cell responses," Proceedings of the National Academy of Sciences of the United States of America, vol. 106, no. 13, pp. 5300-5305, 2009.

[74] J. M. Moffat, T. Gebhardt, P. C. Doherty, S. J. Turner, and J. D. Mintern, "Granzyme a expression reveals distinct cytolytic CTL subsets following influenza A virus infection," European Journal of Immunology, vol. 39, no. 5, pp. 1203-1210, 2009.

[75] S. S. Metkar, C. Menaa, J. Pardo, et al., "Human and mouse granzyme A induce a proinflammatory cytokine response," Immunity, vol. 29, no. 5, pp. 720-733, 2008.

[76] N. L. La Gruta, K. Kedzierska, J. Stambas, and P. C. Doherty, "A question of self-preservation: immunopathology in influenza virus infection," Immunology and Cell Biology, vol. 85, no. 2, pp. 85-92, 2007.

[77] G. F. Rimmelzwaan, A. C. M. Boon, J. T. M. Voeten, E. G. M. Berkhoff, R. A. M. Fouchier, and A. D. M. E. Osterhaus, "Sequence variation in the influenza A virus nucleoprotein associated with escape from cytotoxic T lymphocytes," Virus Research, vol. 103, no. 1-2, pp. 97-100, 2004.

[78] E. G. M. Berkhoff, M. M. Geelhoed-Mieras, M. Jonges, et al., "An amino acid substitution in the influenza A virus hemagglutinin associated with escape from recognition by human virus-specific CD4 ${ }^{+}$T-cells," Virus Research, vol. 126, no. 1-2, pp. 282-287, 2007.
[79] B. Korber, M. LaBute, and K. Yusim, "Immunoinformatics comes of age," PLoS Computational Biology, vol. 2, no. 6, article e71, 2006.

[80] B. Peters, J. Sidney, P. Bourne, et al., "The immune epitope database and analysis resource: from vision to blueprint," PLoS Biology, vol. 3, no. 3, article e91, 2005.

[81] R. Vita, L. Zarebski, J. A. Greenbaum, et al., "The immune epitope database 2.0," Nucleic Acids Research, vol. 38, supplement 1, pp. D854-D862, 2009.

[82] N. Salimi and R. Vita, "The biocurator: connecting and enhancing scientific data," PLoS Computational Biology, vol. 2, no. 10, article e125, 2006.

[83] R. Vita, K. Vaughan, L. Zarebski, et al., "Curation of complex, context-dependent immunological data," BMC Bioinformatics, vol. 7, article 341, 2006.

[84] B. Peters and A. Sette, "Integrating epitope data into the emerging web of biomedical knowledge resources," Nature Reviews Immunology, vol. 7, no. 6, pp. 485-490, 2007.

[85] H.-H. Bui, B. Peters, E. Assarsson, I. Mbawuike, and A. Sette, "Ab and $\mathrm{T}$ cell epitopes of influenza A virus, knowledge and opportunities," Proceedings of the National Academy of Sciences of the United States of America, vol. 104, no. 1, pp. 246-251, 2007.

[86] J. A. Greenbaum, M. F. Kotturi, Y. Kim, et al., "Pre-existing immunity against swine-origin $\mathrm{H} 1 \mathrm{~N} 1$ influenza viruses in the general human population," Proceedings of the National Academy of Sciences of the United States of America, vol. 106, no. 48, pp. 20365-20370, 2010.

[87] S. Stevanovic, "Antigen processing is predictable: from genes to T cell epitopes," Transplant Immunology, vol. 14, no. 3-4, pp. 171-174, 2005.

[88] J. C. Tong, T. W. Tan, and S. Ranganathan, "Methods and protocols for prediction of immunogenic epitopes," Briefings in Bioinformatics, vol. 8, no. 2, pp. 96-108, 2007.

[89] V. Brusic, V. B. Bajic, and N. Petrovsky, "Computational methods for prediction of T-cell epitopes-a framework for modelling, testing, and applications," Methods, vol. 34, no. 4, pp. 436-443, 2004.

[90] C. Lundegaard, O. Lund, C. Kesmir, S. Brunak, and M. Nielsen, "Modeling the adaptive immune system: predictions and simulations," Bioinformatics, vol. 23 , no. 24 , pp. 32653275, 2007.

[91] H. H. Lin, S. Ray, S. Tongchusak, E. L. Reinherz, and V. Brusic, "Evaluation of MHC class I peptide binding prediction servers: applications for vaccine research," BMC Immunology, vol. 9, article 8, 2008.

[92] L. Moise and A. S. De Groot, "Putting immunoinformatics to the test," Nature Biotechnology, vol. 24, no. 7, pp. 791-792, 2006.

[93] M. Moutaftsi, B. Peters, V. Pasquetto, et al., "A consensus epitope prediction approach identifies the breadth of murine TCD8 $8^{+}$-cell responses to vaccinia virus," Nature Biotechnology, vol. 24, no. 7, pp. 817-819, 2006.

[94] C. Lundegaard, M. Nielsen, and O. Lund, "The validity of predicted T-cell epitopes," Trends in Biotechnology, vol. 24, no. 12 , pp. 537-538, 2006.

[95] A. S. De Groot, M. Ardito, E. M. McClaine, L. Moise, and W. D. Martin, "Immunoinformatic comparison of T-cell epitopes contained in novel swine-origin influenza A (H1N1) virus with epitopes in 2008-2009 conventional influenza vaccine," Vaccine, vol. 27, no. 42, pp. 5740-5747, 2009.

[96] I. A. Doytchinova and D. R. Flower, "Class I T-cell epitope prediction: improvements using a combination of 
proteasome cleavage, TAP affinity, and MHC binding," Molecular Immunology, vol. 43, no. 13, pp. 2037-2044, 2006.

[97] G. L. Zhang, N. Petrovsky, C. K. Kwoh, J. T. August, and V. Brusic, "PRED(TAP): a system for prediction of peptide binding to the human transporter associated with antigen processing," Immunome Research, vol. 2, article 3, 2006.

[98] V. Brusic, J. T. August, and N. Petrovsky, "Information technologies for vaccine research," Expert Review of Vaccines, vol. 4, no. 3, pp. 407-417, 2005.

[99] J. C. Tong and E. C. Ren, "Immunoinformatics: current trends and future directions," Drug Discovery Today, vol. 14, no. 13-14, pp. 684-689, 2009.

[100] J. E. McElhaney, D. Xie, W. D. Hager, et al., "T cell responses are better correlates of vaccine protection in the elderly," Journal of Immunology, vol. 176, no. 10, pp. 6333-6339, 2006.

[101] J. E. McElhaney, C. Ewen, X. Zhou, et al., "Granzyme B: correlates with protection and enhanced CTL response to influenza vaccination in older adults," Vaccine, vol. 27, no. 18, pp. 2418-2425, 2009.

[102] D. M. Carragher, D. A. Kaminski, A. Moquin, L. Hartson, and T. D. Randall, "A novel role for non-neutralizing antibodies against nucleoprotein in facilitating resistance to influenza virus," Journal of Immunology, vol. 181, no. 6, pp. 4168-4176, 2008.

[103] G. F. Rimmelzwaan, R. A. Fouchier, and A. D. Osterhaus, "Influenza virus-specific cytotoxic T lymphocytes: a correlate of protection and a basis for vaccine development," Current Opinion in Biotechnology, vol. 18, no. 6, pp. 529-536, 2007.

[104] G. F. Rimmelzwaan and J. E. McElhaney, "Correlates of protection: novel generations of influenza vaccines," Vaccine, vol. 26, supplement 4, pp. D41-D44, 2008.

[105] A. J. McMichael, F. M. Gotch, G. R. Noble, and P. A. S. Beare, "Cytotoxic T-cell immunity to influenza," New England Journal of Medicine, vol. 309, no. 1, pp. 13-17, 1983.

[106] T. Sonoguchi, H. Naito, and M. Hara, "Cross-subtype protection in humans during sequential, overlapping, and/or concurrent epidemics caused by H3N2 and H1N1 influenza viruses," Journal of Infectious Diseases, vol. 151, no. 1, pp. 8188, 1985.

[107] S. L. Epstein, "Prior H1N1 influenza infection and susceptibility of Cleveland Family Study participants during the H2N2 pandemic of 1957: an experiment of nature," Journal of Infectious Diseases, vol. 193, no. 1, pp. 49-53, 2006.

[108] J. Jameson, J. Cruz, M. Terajima, and F. A. Ennis, "Human $\mathrm{CD}^{+}$and $\mathrm{CD}^{+} \mathrm{T}$ lymphocyte memory to influenza a viruses of swine and avian species," Journal of Immunology, vol. 162, no. 12, pp. 7578-7583, 1999.

[109] A. C. M. Boon, G. De Mutsert, D. Van Baarle, et al., "Recognition of homo- and heterosubtypic variants of influenza A viruses by human CD8 ${ }^{+}$T lymphocytes," Journal of Immunology, vol. 172, no. 4, pp. 2453-2460, 2004.

[110] J. H. C. M. Kreijtz, G. De Mutsert, C. A. Van Baalen, R. A. M. Fouchier, A. D. M. E. Osterhaus, and G. F. Rimmelzwaan, "Cross-recognition of avian H5N1 influenza virus by human cytotoxic T-lymphocyte populations directed to human influenza A virus," Journal of Virology, vol. 82, no. 11, pp. 5161-5166, 2008.

[111] G. F. Rimmelzwaan, J. H. C. M. Kreijtz, R. Bodewes, R. A. M. Fouchier, and A. D. M. E. Osterhaus, "Influenza virus CTL epitopes, remarkably conserved and remarkably variable," Vaccine, vol. 27, no. 45, pp. 6363-6365, 2009.

[112] D. L. Bolton and M. Roederer, "Flow cytometry and the future of vaccine development," Expert Review of Vaccines, vol. 8, no. 6, pp. 779-789, 2009.
[113] J. E. McElhaney, S. Gravenstein, C. M. Upshaw, et al., "Granzyme B: a marker of risk for influenza in institutionalized older adults," Vaccine, vol. 19, no. 27, pp. 3744-3751, 2001.

[114] C. Ewen, K. P. Kane, I. Shostak, et al., "A novel cytotoxicity assay to evaluate antigen-specific CTL responses using a colorimetric substrate for Granzyme B," Journal of Immunological Methods, vol. 276, no. 1-2, pp. 89-101, 2003.

[115] B. Z. Packard and A. Komoriya, "Intracellular protease activation in apoptosis and cell-mediated cytotoxicity characterized by cell-permeable fluorogenic protease substrates," Cell Research, vol. 18, no. 2, pp. 238-247, 2008.

[116] K. T. Brunner, J. Mauel, J. C. Cerottini, and B. Chapuis, "Quantitative assay of the lytic action of immune lymphoid cells on 51-Cr-labelled allogeneic target cells in vitro; inhibition by isoantibody and by drugs," Immunology, vol. 14, no. 2, pp. 181-196, 1968.

[117] A. Chahroudi, G. Silvestri, and M. B. Feinberg, "Measuring $\mathrm{T}$ cell-mediated cytotoxicity using fluorogenic caspase substrates," Methods, vol. 31, no. 2, pp. 120-126, 2003.

[118] K. R. Jerome, D. D. Sloan, and M. Aubert, "Measurement of CTL-induced cytotoxicity: the caspase 3 assay," Apoptosis, vol. 8, no. 6, pp. 563-571, 2003.

[119] C. A. van Baalen, R. A. Gruters, E. G. M. Berkhoff, A. D. M. E. Osterhaus, and G. F. Rimmelzwaan, "FATT-CTL assay for detection of antigen-specific cell-mediated cytotoxicity," Cytometry Part A, vol. 73, no. 11, pp. 1058-1065, 2008.

[120] K. Chen, L. Chen, P. Zhao, et al., "FL-CTL assay: fluorolysometric determination of cell-mediated cytotoxicity using green fluorescent protein and red fluorescent protein expressing target cells," Journal of Immunological Methods, vol. 300, no. 1-2, pp. 100-114, 2005.

[121] D. L. Barber, E. J. Wherry, and R. Ahmed, "Cutting edge: rapid in vivo killing by memory CD8 T cells," Journal of Immunology, vol. 171, no. 1, pp. 27-31, 2003.

[122] K. M. Grebe, J. W. Yewdell, and J. R. Bennink, "Heterosubtypic immunity to influenza A virus: where do we stand?" Microbes and Infection, vol. 10, no. 9, pp. 1024-1029, 2008.

[123] R. Bodewes, J. H. Kreijtz, and G. F. Rimmelzwaan, "Yearly influenza vaccinations: a double-edged sword?" The Lancet Infectious Diseases, vol. 9, no. 12, pp. 784-788, 2009.

[124] L. Corbeel, "Should healthy children be vaccinated against influenza? Comments about this query," European Journal of Pediatrics, vol. 166, no. 6, pp. 629-631, 2007.

[125] T. Heikkinen, R. Booy, M. Campins, et al., "Should healthy children be vaccinated against influenza? A consensus report of the Summits of Independent European Vaccination Experts," European Journal of Pediatrics, vol. 165, no. 4, pp. 223-228, 2006.

[126] L. Moral and E. M. Rubio, "We will have to vaccinate healthy children against influenza when we know that it is helpful," European Journal of Pediatrics, vol. 165, no. 11, p. 817, 2006.

[127] T. Heikkinen and V. Peltola, "Influenza vaccination of children," The Lancet Infectious Diseases, vol. 9, no. 12, pp. 720-721, 2009.

[128] A. S. De Groot, "Immunomics: discovering new targets for vaccines and therapeutics," Drug Discovery Today, vol. 11, no. 5-6, pp. 203-209, 2006.

[129] A. Sette and B. Peters, "Immune epitope mapping in the post-genomic era: lessons for vaccine development," Current Opinion in Immunology, vol. 19, no. 1, pp. 106-110, 2007. 
[130] E. Stern, E. R. Steenblock, M. A. Reed, and T. M. Fahmy, "Label-free electronic detection of the antigen-specific T-cell immune response," Nano Letters, vol. 8, no. 10, pp. 33103314, 2008.

[131] Y. Soen, D. S. Chen, D. L. Kraft, M. M. Davis, and P. O. Brown, "Detection and characterization of cellular immune responses using peptide-MHC microarrays," PLoS Biology, vol. 1, no. 3, article E65, 2003. 


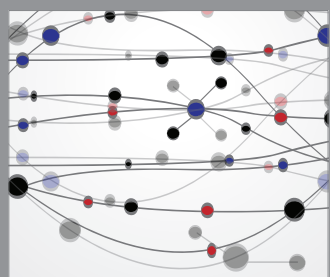

The Scientific World Journal
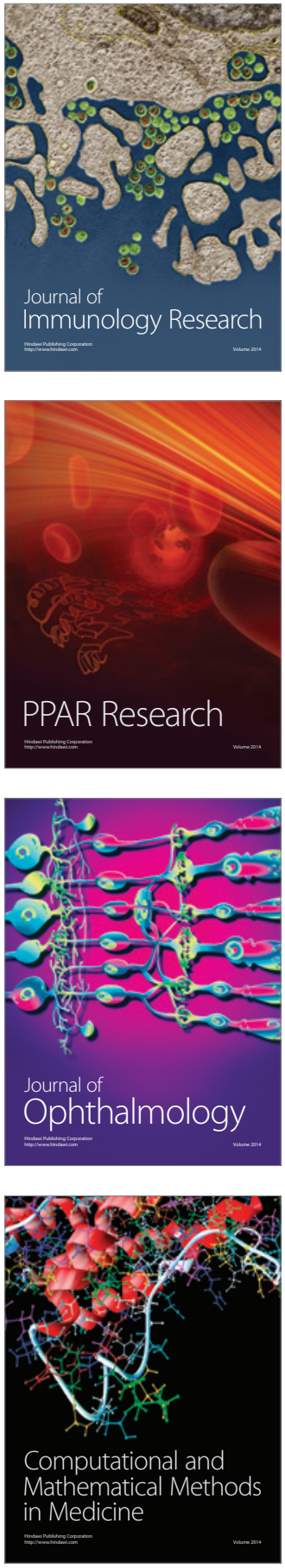

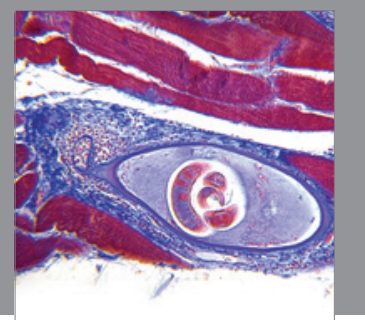

Gastroenterology

Research and Practice
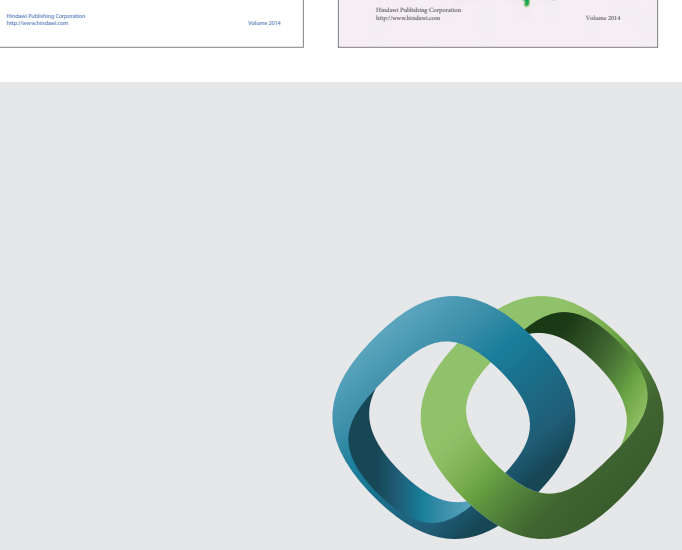

\section{Hindawi}

Submit your manuscripts at

http://www.hindawi.com
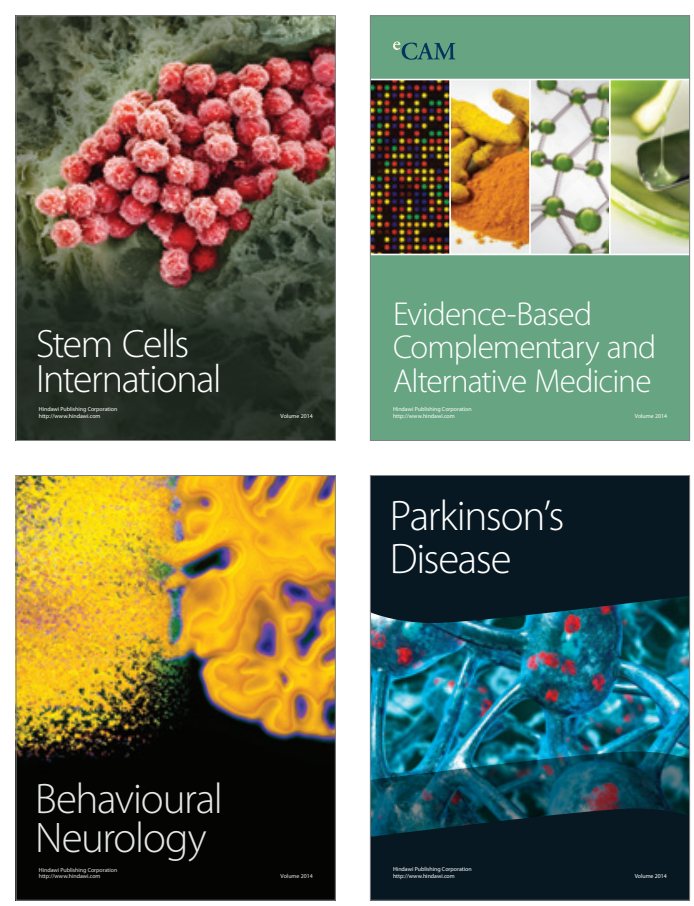

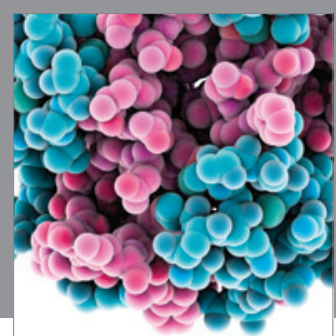

Journal of
Diabetes Research

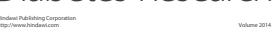

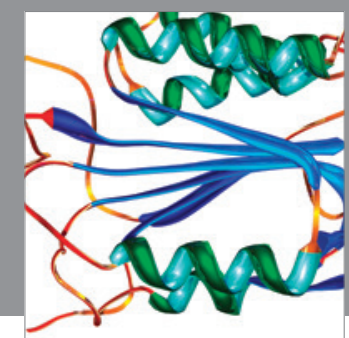

Disease Markers
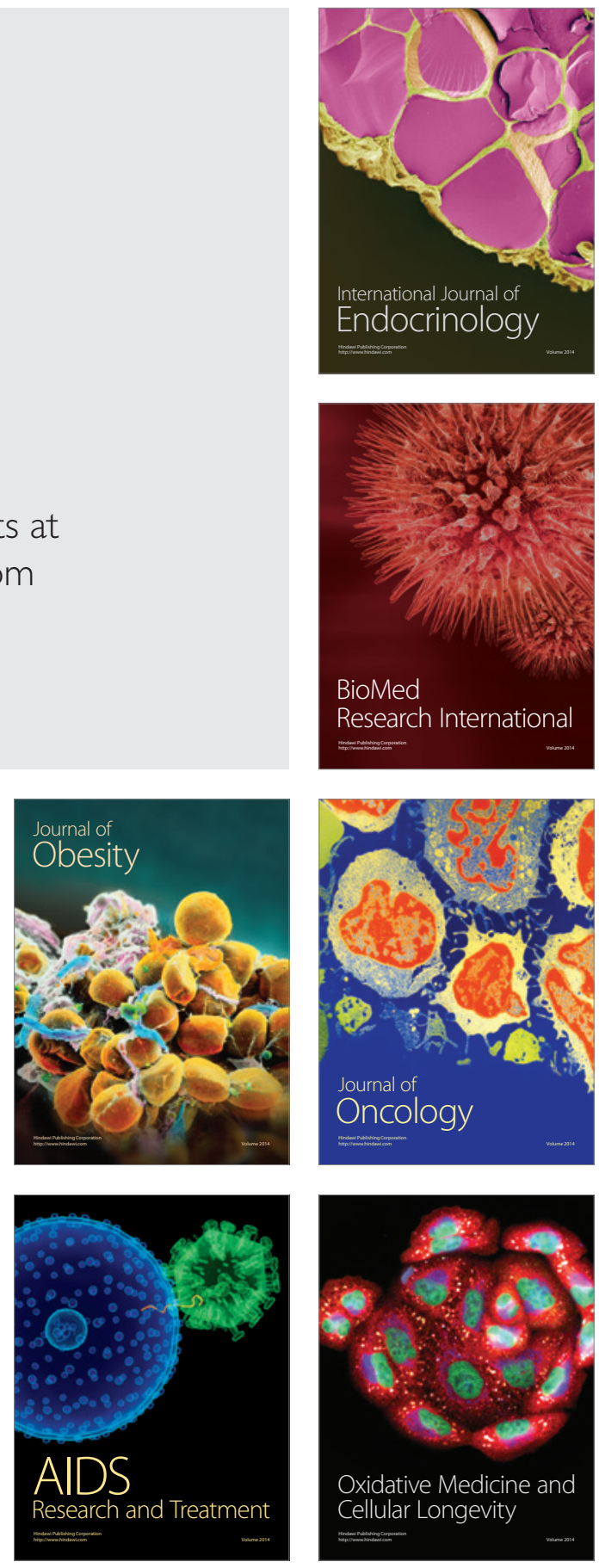